\title{
A Multi-Point Measurement Method for Thermal Characterization of Foil Bearings Using Customized Thermocouples
}

\author{
MICHAł LUBIENIECKI, ${ }^{1,3,4}$ JAKUB ROEMER, ${ }^{1}$ ADAM MARTOWICZ, ${ }^{1}$ \\ KRZYSZTOF WOJCIECHOWSKI, ${ }^{2}$ and TADEUSZ UHL ${ }^{1}$
}

1.-Department of Robotics and Mechatronics, AGH University of Science and Technology, Al. A. Mickiewicza 30, 30-059 Kraków, Poland. 2.-Thermoelectric Research Laboratory, Faculty of Materials Science and Ceramics, AGH University of Science and Technology, Al. A. Mickiewicza 30,30-059 Kraków, Poland. 3.—e-mail: lubienie@agh.edu.pl. 4.—e-mail: michal.lubieniecki@ agh.edu.pl

Gas foil bearings have become widespread covering the applications of microturbines, motors, compressors, and turbocharges, prevalently of small size. The specific construction of the bearing, despite all of its advantages, makes it vulnerable to a local difference in heat generation rates that can be extremely detrimental. The developing thermal gradients may lead to thermal runaway or seizure that eventually causes bearing failure, usually abrupt in nature. The authors propose a method for thermal gradient removal with the use of current-controlled thermoelectric modules. To fulfill the task of control law adoption the numerical model of the heat distribution in a bearing has been built. Although sparse readings obtained experimentally with standard thermocouples are enough to determine thermal gradients successfully, validation of the bearing numerical model may be impeded. To improve spatial resolution of the experimental measurements the authors proposed a matrix of customized thermocouples located on the top foil. The foil acts as a shared conductor for each thermocouple that reduces the number of cable connections. The proof of concept of the control and measurement systems has been demonstrated in a still bearing heated by a cartridge heater.

Key words: Smart structures, foil bearings, active cooling, Peltier modules, thermoelectricity

\section{INTRODUCTION}

The gas foil bearings (GFB) are typically applied in small, lightly loaded, high speed rotating machinery. ${ }^{1}$ Apart from the advantages they exhibit, they are also subjected to failure due to three main reasons, ${ }^{2}$ i.e. overheating, thermal runaway, and excessive temperature inequalities of the foil. The developing thermal gradient is most dangerous as it may unexpectedly occur while changing speed or load of a stable bearing. In addition, thermal gradients can cause instability at any temperature, not necessarily only at elevated temperatures.

(Received June 11, 2015; accepted September 19, 2015; published online October 22, 2015)
Currently, mitigating thermal stability problems is equivalent to cooling the whole bearing with forced air flow. The cooling stream may be directed at the journal surface (direct cooling), may be injected inside the hollow shaft (indirect cooling), forced to flow through the foil bumps (axial cooling) ${ }^{3}$ or can be pointed on the shaft through the set of radially distributed nozzles (radial cooling). ${ }^{4}$ All abovementioned methods successfully lower the temperature of the bearing while decreasing the axial thermal gradient at the same time, but axial cooling that is likely to increase the gradient. Only radial cooling provides means for controllable gradient removal.

In this article the authors demonstrate an active system for control of the temperature distribution 
on the top foil surface. Adoption of the control law determining the modules' currents requires extensive numerical effort. Hence, the numerical model needs to be thoroughly validated. For the purpose of this task, the customized thermocouples have been prepared and tested.

\section{ENHANCED CONSTRUCTION OF FOIL BEARINGS}

Foil bearings fall into the category of journal bearings. In contrast to the typical construction of such bearings for which the shaft rotates in a stiff cartridge, in GFB the shaft and the bushing are separated by a set of thin and flexible foils (Fig. 1). The investigated bearing contains foils of $0.1-\mathrm{mm}$ thickness made of Inconel 618 . The surface of foil that is in contact with the shaft is additionally covered with a fluoropolymer coating AS20 for better frictional properties.

In order to control the temperature distribution on the foils inside a bearing, a novel construction of the bearing cartridge has been proposed (Fig. 2). The stiff cartridge has been divided into sections. A total of 36 Peltier modules (A) were glued between the inner (B) and outer bushing (C) in four planes on the bearing circumference. The outer cartridge has been broken down into three pieces for assembly reasons. Inspection holes (D) for temperature measurement of the foils are located in between the thermoelectric modules. A total of 21 classical thermocouples can be used in groups of three and four every $120^{\circ}$ for top and bump foil measurement, respectively.

\section{REDUCTION OF THERMAL GRADIENT WITH LOCAL COOLING APPROACH}

Conducting a numerical analysis is essential to study the relationship between the currents supplied to the individual thermoelectric module and the temperature distribution on the bump and top foils for defining the control law based on a limited number of measurement points. A numerical model (Finite Element Modeling) for a foil bearing enhanced by thermoelectric coolers was created in ANSYS environment, in which an analytical model of thermoelectric modules has been implemented. ${ }^{5}$ The specific bearing working conditions have been accounted for by using varied heat generation rates in air film slices. The total heat generation matched with bearing frictional moment known from its experimental characterization. With the adopted approach, no hydrodynamic modelling was needed, only the steady state thermal analysis was performed.

The preliminary results were obtained for six arbitrarily chosen groups of thermoelectric modules, which were localized in proximity to the region of the highest temperatures as presented in Fig. $3 .^{6}$ Each group covers four thermoelectric modules spread axially for a given circumferential localization. Having introduced the maximum allowed current (preferably 1A according to the modules' properties), enumeration of densely distributed current configurations operating with the determined metamodel led to the following most effective configuration: $I=0.8$ A for the modules in the group P3 and $I=1 \mathrm{~A}$ for the group P4. The comparison between the temperature profiles for initial and most effective configurations are shown in Fig. 3c. The temperature scatter decreased from $15.6^{\circ} \mathrm{C}$ down to $10.5^{\circ} \mathrm{C}$, which means a reduction of $32.7 \%$. The maximum temperature for the whole bearing was even slightly reduced from $39.5^{\circ} \mathrm{C}$ down to $38.9^{\circ} \mathrm{C}$, which is an additional advantage of the found current configuration. However, an increase of this temperature should not be considered critical for the operation characteristics according to data reported in Ref. 2.

Further numerical studies require better characterization of the temperature distribution in a bearing also due to steep characteristic of the temperature along the circumference direction.
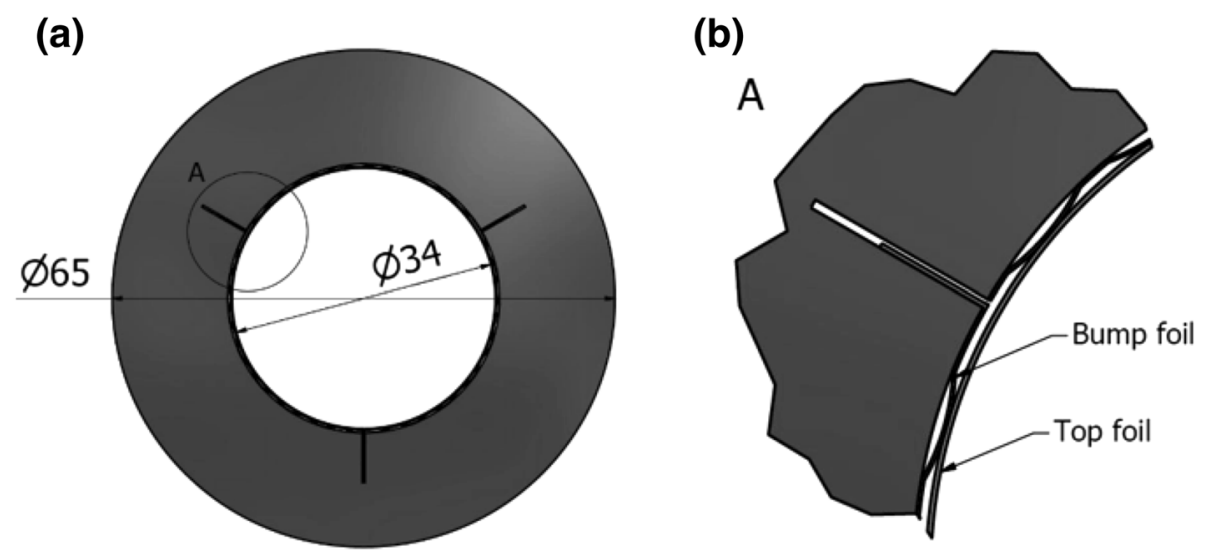

Fig. 1. Typical foil bearing construction; (a) the bearing front view; (b) closeup view of the selected section A showing details of foils and mounting slots. 
(a)

(b)

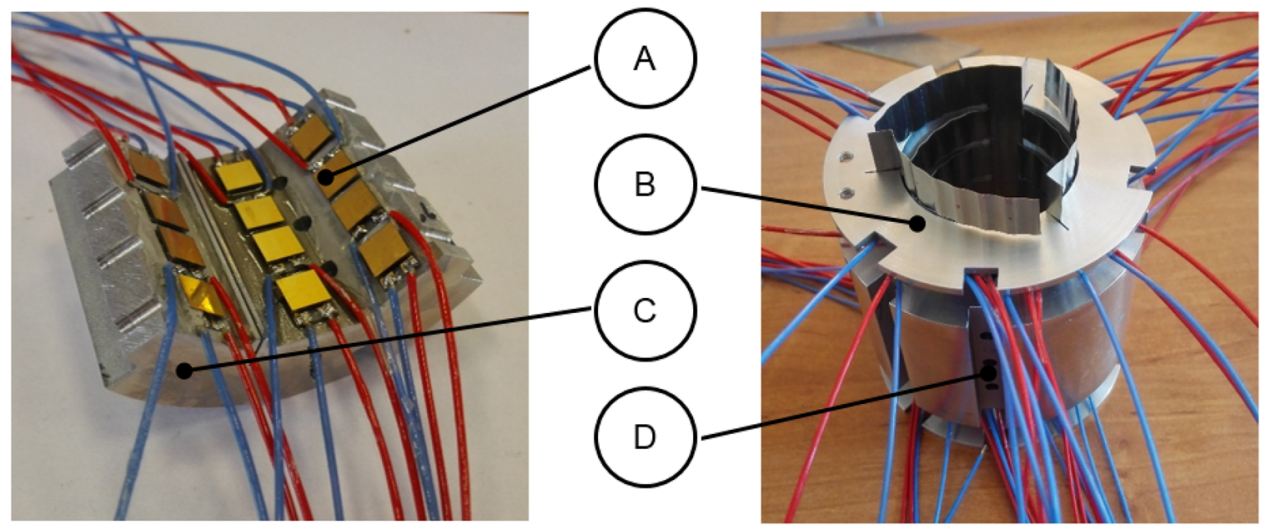

Fig. 2. (a) The part of the outer bushing with Peltier modules mounted; (b) the bearing with visible bump foil during assembly; the consecutive bearing parts are marked as follows: Peltier modules $(A)$, inner bushing (B), outer bushing (C), and inspection holes (D).
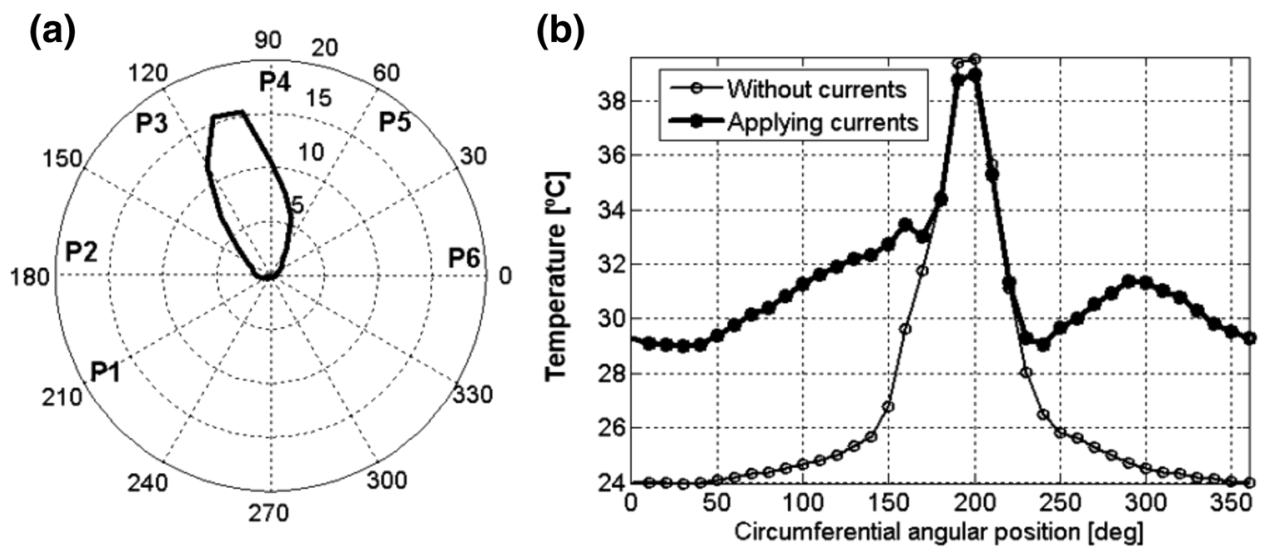

Fig. 3. (a) Temperature profile in polar coordinate system; (b) possible reduction of circumferential temperature profile for the top foil. ${ }^{6}$

\section{METHOD OF MEASUREMENT OF TEMPERATURE DISTRIBUTION}

The foils in the bearing are made of Inconel 618, which is basically a Ni-Cr alloy of high resistance for oxidation and corrosion. The nominal chemical composition of the material $(\mathrm{Ni}, 82.5 \%$; $\mathrm{Cr}, 15 \%$; $\mathrm{Fe}, 6 \%$;, $0.05 \%$ ) is close to the composition of $\mathrm{Ni}$ $\mathrm{Cr}$ solid solutions commonly used in $K$-type thermocouples $(\mathrm{Ni}, 90 \%$ and $\mathrm{Cr}, 10 \%)$. Therefore, because of similar chemical and physical properties, it was decided on the original solution in which the top foil of the bearing serves also as an element of thermocouples. Pure Pt was selected as a reference material of thermocouples. The $0.1 \mathrm{~mm} \mathrm{Pt}$ wires were directly joined at 40 evenly spaced points on the surface of the top foil of the bearing. Measuring potentials between particular $\mathrm{Pt}$ wires one can directly determine temperature differences between selected points. The advantage of the applied configuration is a very precise measurement of temperature exactly at the working surface of the foil, as well as double reduction of the number of measurement wires in comparison to the solution in which typical thermocouples would be applied.

The absolute Seebeck coefficient of Inconel 618 is not given by the producer. Moreover, the produced Pt-Inconel junctions can have slightly different properties. Therefore, it was decided to calibrate each of the produced thermocouples separately. The electromotive forces were measured for the reference temperature $T_{\mathrm{C}}=20^{\circ} \mathrm{C}$ and temperatures of foil $T_{\mathrm{H}}: 40^{\circ} \mathrm{C}, 60^{\circ} \mathrm{C}, 80^{\circ} \mathrm{C}, 100^{\circ} \mathrm{C}, 120^{\circ} \mathrm{C}, 140^{\circ} \mathrm{C}$. It was concluded that measured voltages changed almost proportionally to the applied temperature differences; therefore, to estimate the Seebeck coefficient for each thermocouple, linear regression has been applied. Measured thermopowers are in the range of 8 and $10 \mu \mathrm{VK}^{-1}$. The estimated average standard deviation is less than $0.4 \mu \mathrm{VK}^{-1}(\sim 4 \%)$, which gives the same precision of the thermocouples as temperature sensors. 


\section{EXPERIMENTAL DEMONSTRATION}

The experimental setup (Fig. 4) consisted of a bearing assembly (A), the shaft with a heater (B) for inducing thermal gradients, current source (C) for thermoelectric modules, data acquisition unit (D) and control unit (E).

The conducted test involved heating up the bearing with a cartridge heater dissipating $2 \mathrm{~W}$ of heat that equals the amount of heat conducted to the bearing's bushing during its normal operation. After having reached a steady state, the control currents were set according to the scheme described in section 3 . The temperature measurements were taken when minimum temperature was noted, after reaching the new steady state, right after the modules are switched off and in steady state again.

\section{DISCUSSION OF RESULTS AND CONCLUSIONS}

The results obtained during experiment prove that bearing characterization with custom made thermocouples that use a top foil as a conductor may be successfully applied to investigating the internal temperature distribution of the foil bearing. It is important that the adopted approach eliminates the uncertainty of the measurement location. The other advantage is that a top foil temperature reading is accessible without the need for notching the bump foil that is a common practice and that certainly affects the mechanical properties of the bearing. Although the measured circumferential temperature distribution (Fig. 5) reflect nature of the profile obtained numerically (Fig. 3), the resultant gradient differs significantly. This is due to incomparable heat flux distribution in working bearing and those evoked by a cartridge heater.

The crucial flaw of the adopted approach is the ease with which the thermocouples can be damaged. During the manual assembly process, nearly half of the prepared thermocouples got damaged. When this issue is solved, the spatial resolution of the measurement can be substantially increased with the use of custom thermocouples.

The results of the temperature regulation are shown on Fig. 6. It is clearly seen that initial gradient of $2.8^{\circ} \mathrm{C}$ has been reduced to $1.1^{\circ} \mathrm{C}$ to finally stabilize at a level of $1.4^{\circ} \mathrm{C}$. The small increase in the absolute temperature of the bearing is because additional heat is constantly delivered to the bearing by the Joule effect. After switching off the regulator, the temperature gradient instantly rises to $2.6^{\circ} \mathrm{C}$ to finally stabilize at a level of $3.3^{\circ} \mathrm{C}$. The absolute temperature difference for the reference reading and last taken measurement stems from the fact that bearing temperature was slowly, but constantly increasing during the test.

The use of custom thermocouples integrated with top foil can greatly affect the insight we have on temperature distribution inside the foil bearings. However, the bearing assembly process has to be adjusted. On the other hand, the thermoelectric modules have potential for gradient removal from a

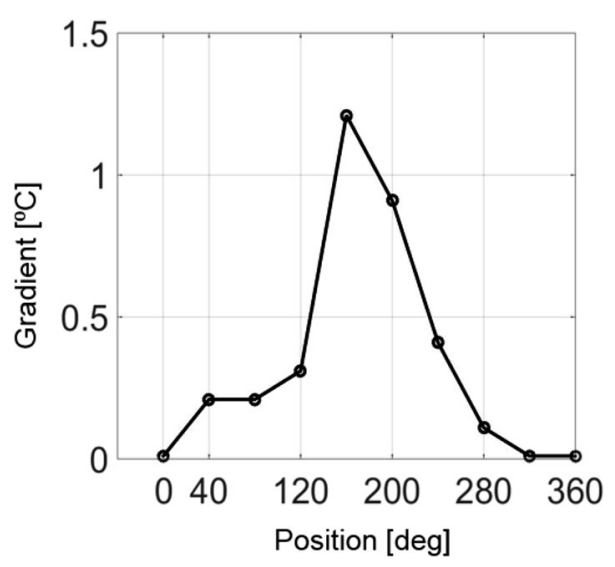

Fig. 5. The measured circumferential thermal gradient. (a)

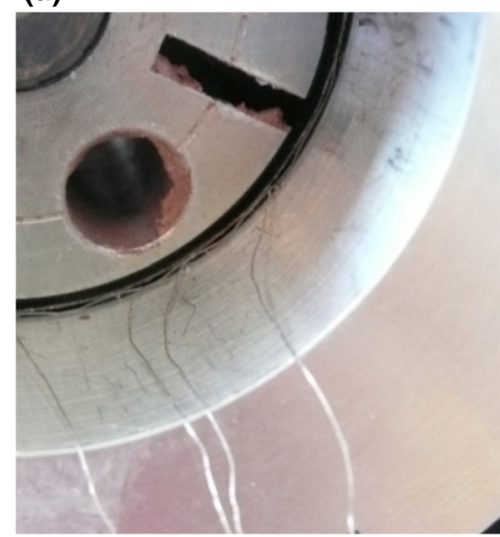

(b)

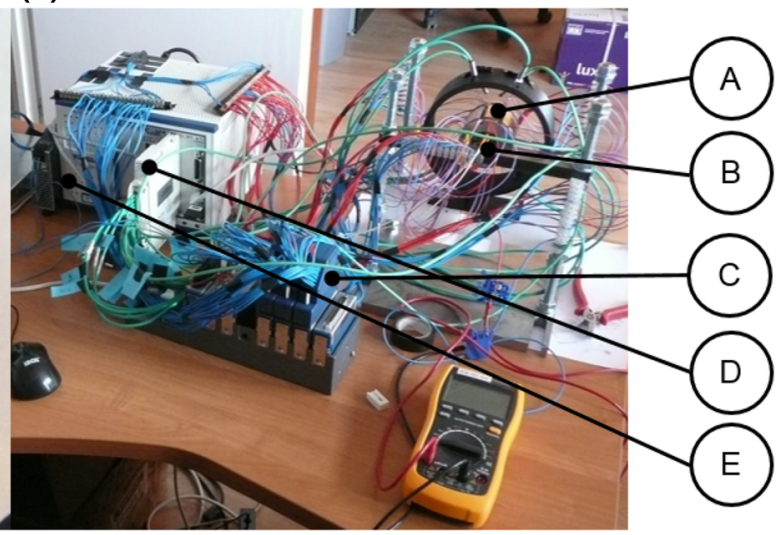

Fig. 4. (a) Close-up view of the bearing assembly-the Pt wires constituting the custom thermocouples are clearly visible; (b) the complete laboratory setup with control and acquisition unit: $(A)$ the bearing assembly with a heater (B), current source (C) for thermoelectric modules, thermocouple acquisition unit (D), and current controller (E). 
(a)

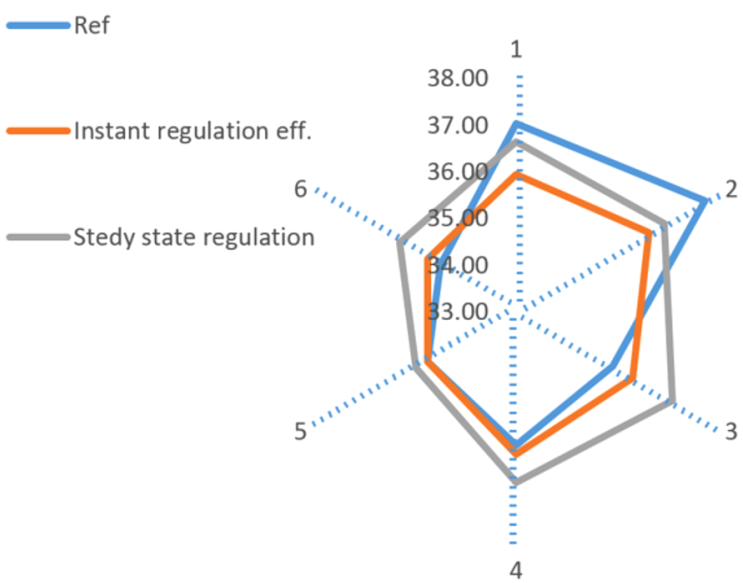

(b)

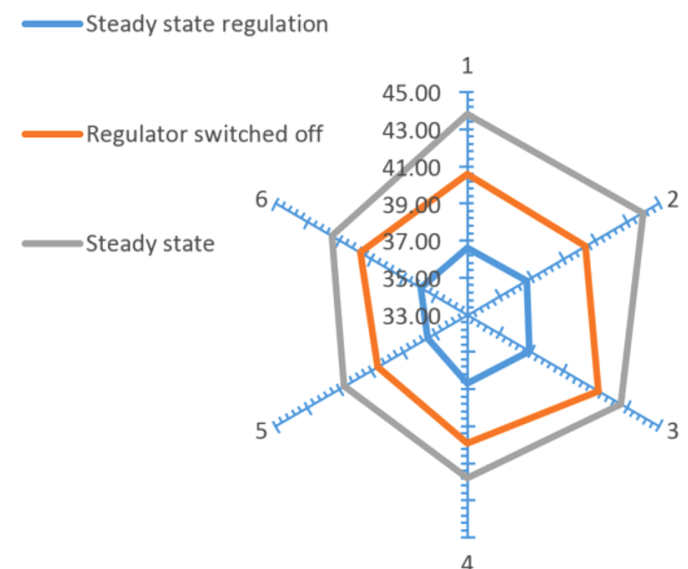

Fig. 6. (a) The thermal gradient obtained experimentally for the reference case (uneven shaft heating), after regulation begins (orange) and in steady state with control currents still applied to the modules (grey); (b) the thermal gradient during the regulation (blue; corresponding to the grey curve in part a), immediately after the regulation is disabled (orange) and in a steady state (grey).

bearing foils. The experimental study on rotating bearing must be conducted.

\section{ACKNOWLEDGEMENT}

The authors acknowledge the project "The use of thermoelectric materials to improve thermal stability of high-speed rotor bearings systems", No. PBS1/A6/6/2012 financed by the National Centre for Researched and Development.

\section{OPEN ACCESS}

This article is distributed under the terms of the Creative Commons Attribution 4.0 International License (http://creativecommons.org/licenses/by/4.0/ ), which permits unrestricted use, distribution, and reproduction in any medium, provided you give appropriate credit to the original author(s) and the source, provide a link to the Creative Commons license, and indicate if changes were made.

\section{REFERENCES}

1. D. Kim, A. Lee, and B. Choi, J. Eng. Gas Turbine Power 136, 032504 (2013).

2. K. Radi, C. Batcho (2010), A Novel thermal management approach for radial foil air bearings, Available via Defense Technical Information Center, http://www.dtic.mil/cgi-bin/ GetTRDoc?Location=U2\&doc=GetTRDoc. pdf\&AD=ADA527 54, Accessed 01 June 2015.

3. K. Radil, C. Dellacorte, and M. Zeszotek, Tribol. Trans., 50(3) (2007).

4. S. Shrestha (Dissertation, The University of Texas at Arlington, 2012)

5. J. Roemer, M. Lubieniecki, D. Polaczek, M. Miodunka, and T. Uhl (Paper presented at XIV Mechatronic Workshop, Kraków, 2-3 June 2014).

6. J. Roemer, M. Lubieniecki, A. Martowicz, and T. Uhl, Proceedings of 7th ECCOMAS Thematic Conference on Smart Structures and Materials, (Ponta Delgada, June 03-06, 2015). 